\title{
Cell Subpopulations Overexpressing p75NTR Have Tumor-initiating Properties in the C6 Glioma Cell Line
}

\author{
WEI-HSUN YANG ${ }^{1,2}$, CHUN-YU CHENG $^{1,3}$, MIAO-FEN CHEN $^{4}$ and TING-CHUNG WANG ${ }^{1,2}$ \\ ${ }^{1}$ Division of Neurosurgery, Department of Surgery, Chang Gung Memorial Hospital, Chiayi, Taiwan, R.O.C.; \\ ${ }^{2}$ Graduate Institute of Clinical Medical Sciences, College of Medicine, \\ Chang Gung University, Taoyuan, Taiwan, R.O.C.; \\ ${ }^{3}$ College of Medicine, Chang Gung University, Taoyuan, Taiwan, R.O.C.; \\ ${ }^{4}$ Department of Radiation Oncology, Chang Gung Memorial Hospital, Chiayi, Taiwan, R.O.C.
}

\begin{abstract}
Background/Aim: Glioma is the most common and lethal primary brain tumor. Even with the development of multidisciplinary treatment approaches, results are disappointing because of the unavoidable tumor recurrence, which may be caused by the existence of tumor-initiating cells. The p75 neurotrophin receptor ( $p 75 N T R)$, which belongs to the tumor necrosis factor receptor superfamily, is not only involved in various cellular functions but also related to tumor growth. This study is focused, on the possible role of p75NTR in glioma tumor initiation. Materials and Methods: C6 cells with high and low expression of $p 75 N T R$ were sorted using flow cytometry. The neurosphere characteristics and properties of these two subpopulations were assessed and compared with those of parental cells. Radiation and chemotherapy sensitivity was also analyzed in these cell populations. Finally, in vivo tumorigenicity of cells was tested in a rat model. Results: Cells overexpressing p75NTR (C6p75+++ cells) demonstrated greater ability of neurosphere formation, colony proliferation, and certain stem cell marker overexpression than cells with low p75NTR expression (C6p75+) and parental cells. In addition, following irradiation or temozolomide treatment, more viable C6p $75+++$ cells remained, and they proliferated into more colonies. In vivo, C6p75+++ cell implantation in Sprague
\end{abstract}

Abbreviations: BTICs: brain tumor-initiating cells.

Correspondence to: Ting-Chung Wang, Division of Neurosurgery, Department of Surgery, Chang Gung Memorial Hospital, No 6, West Section, Chia-Pu Road, Putz City, Chia-Yi, Taiwan 613, R.O.C. Tel.: +886 53621000 Ext 3996, Fax: +886 53623002, email: northernblotting@gmail.com

Key Words: C6 glioma, neurotrophin receptor, tumor-initiating properties, neurospheres, radioresistance.
Dawley rats reduced the survival time. Conclusion: Cells with $p 75 N T R$ overexpression demonstrated certain unique characteristics of tumor-initiating cells, such as neurosphere formation, high colony proliferation, and resistance to radioand chemotherapy. With regard to the heterogeneous composition of glioma cells, p75NTR can be used as an alternative marker to identify a glioma subpopulation with tumor-initiating properties.

Gliomas are the most common and deadliest primary brain tumors (1). Even with multidisciplinary treatments, including maximal surgical resection, radiotherapy, and chemotherapy, being developed, their prognosis is usually poor due to their recurrence (2). Major challenges associated with glioma treatment are the highly invasive nature and resistance to radioand chemotherapy. Most patients have a survival time of only 15 months on average because of tumor recurrence (3).

Accumulating evidence has suggested that glioma cell heterogeneity is the main cause of treatment failure (4-7). Among various glioma components, a unique cell subpopulation possesses specific characteristics, such as tumor initiation (8-10), self-renewal (11), and differentiation into heterogeneous cancer cells. This unique subpopulation, labeled as brain tumor-initiating cells (BTICs), can induce resistance to chemo- and radiotherapy and cause tumor recurrence (12-15). Several surface markers, including CD24, CD44 (16, 17), CD133, and ALDH1 (18-21), have been used to identify BTICs. However, because there is no consensus on one marker specific for BTICs, alternative methods to identify these stem-like cells, such as the sphereformation assay, have been developed $(22,23)$.

The p75 neurotrophin receptor (p75NTR) is a transmembrane glycosylated receptor for neurotrophins and proneurotrophins. In the nervous system, it is expressed in neurons, astrocytes, Schwann cells, and oligodendrocytes (24). After binding to neurotrophins, p75NTR participates in various cellular functions, such as cell survival (25), 
neuronal regeneration (26), and cell migration $(27,28)$. Cancer biology studies have shown that p75NTR-expressing melanoma cells have the ability to self-renew and cause tumor growth (29). In esophageal carcinomas, p75NTR is expressed in highly proliferative and undifferentiated tumor cells (30). In hypopharyngeal cancer, p75NTR is associated with tumor initiation and resistance to chemotherapy (31).

With respect to gliomas, our previous study has suggested that p75NTR expression is associated with glioma cell invasiveness and migration in vitro (32). In addition, accumulating evidence from clinical studies has suggested that p75NTR is associated with human glioma invasiveness $(33,34)$. Thus, we proposed that p75NTR plays a role in the tumor initiation of glioma. In the present study, the effects of p75NTR expression on neurosphere formation and stem cell marker expression were evaluated. In addition, radioand chemosensitivity were assessed using cells with high and low p75NTR expression. Finally, the effects of p75NTR on tumor initiation or growth in Sprague Dawley rats were examined.

\section{Materials and Methods}

Cell lines. C6 glioma cell lines were obtained from the American Type Culture Collection (CLL-107, Rockville, MD, USA) and maintained as a monolayer in Dulbecco's modified Eagle's medium (DMEM, Gibco, Grand Island, NY, USA) supplemented with $10 \%$ fetal bovine serum (FBS, Gibco), $100 \mathrm{IU} / \mathrm{ml}$ penicillin G (Gibco, Grand Island, NY, USA), and $100 \mu \mathrm{g} / \mathrm{ml}$ streptomycin (Gibco) at $37^{\circ} \mathrm{C}$ in a humidified $5 \% \mathrm{CO}_{2}$ incubator.

Fluorescence-activated cell sorting (FACS). At 70\%-80\% confluency, C6 cells were washed using trypsin-EDTA and adjusted to a count of $1 \times 10^{6}$. Then, C6 cells were resuspended in staining buffer [1× phosphate-buffered saline (PBS), 1\% FBS, $25 \mathrm{mM}$ HEPES (Sigma-Aldrich, St. Louis, MO, USA), 1 mM EDTA (Cayman chemical, Ellsworth Road Ann Arbor, Michigan, USA)] and incubated with anti-p75NTR antibody (ab8874, Abcam, Cambridge, UK) for $1 \mathrm{~h}$ at room temperature. After washing with staining buffer, cells were incubated with the goat anti-rabbit IgG Alexa Fluor 488 (ab150077, Abcam) antibody in staining buffer for $30 \mathrm{~min}$ at room temperature. Depending on forward- and sidescattered light, small-sized cells, apoptotic cells, and doublets were gated out. Cell sorting was performed using BD FACSAria ${ }^{\mathrm{TM}}$ Fusion (Becton Dickinson Biosciences, San Jose, CA, USA), and results were analyzed using BD FACSDIVA ${ }^{\mathrm{TM}}$ software. The highest and the lowest of $5 \%$ of cells were excluded, then the remaining higher and lower $25 \%$ of p75NTR-expression cells were collected and labeled as C6p75+++ and C6p75+, respectively, and were then maintained in growth medium (DMEM, 10\% FBS, 100 $\mathrm{IU} / \mathrm{ml}$ penicillin $\mathrm{G}$, and $100 \mu \mathrm{g} / \mathrm{ml}$ streptomycin).

Sphere formation assay. C6p75+ and C6p75+++ cells were detached using trypsin-EDTA solution and were washed with PBS to remove serum. Next, cells were suspended in serum-free DMEM/F12 supplemented with $100 \mathrm{IU} / \mathrm{ml}$ penicillin, $100 \mu \mathrm{g} / \mathrm{ml}$ streptomycin, $20 \mathrm{ng} / \mathrm{ml}$ epidermal growth factor (Invitrogen, Grand Island, NY, USA), $10 \mathrm{ng} / \mathrm{ml}$ human recombinant basic fibroblast growth factor, and 2\% B27 supplement. They were subsequently seeded on a Corning ${ }^{\circledR}$ Costar ${ }^{\circledR}$ Ultra-Low attachment plate (Sigma-Aldrich) at $5 \times 10^{3}$ cells/well and were cultivated for 10-14 days. Neurosphere formation was observed every day under a microscope (200x; SMZ1000, Nikon).

Colony formation assay. The soft agar assay was performed in sixwell plates containing two layers of SeaPlaque Agarose (Invitrogen). The bottom layer comprised $0.6 \%$ agarose in $1 \mathrm{ml}$ DMEM with $10 \%$ FBS. C6 parental cells, C6p75+ cells, and C6p75+++ cells were then dissociated at a density of $2 \times 10^{3}$ per well and mixed with $0.3 \%$ agarose. Subsequently, $1.5 \mathrm{ml}$ of the mixture was placed in the six-well plates as the top layer. Cells were cultured for 10 days prior to fixing and staining with $0.5 \mathrm{ml}$ of $0.005 \%$ crystal violet overnight. Colonies containing more than 50 cells were counted under a microscope (SMZ1000, Nikon).

Western blotting. Western blotting was performed as previous studies $(32,35)$. Cells were lysed with lysis buffer [1\% Triton X-100, $50 \mathrm{mM}$ of Tris(PH 7.5), $10 \mathrm{mM}$ EDTA, and protease inhibitor cocktail (Roche, Indianapolis, IN, USA)]. Then cell lysates were centrifugated at $10,000 \times \mathrm{g}, 4^{\circ} \mathrm{C}$ for $20 \mathrm{~min}$. Then the quantified cell lysates were subjected to SDS-PAGE and transferred onto a polyvinylidene difluoride membrane (Millipore, Billerica, MA, USA). After blocking with $8 \%$ non-fat milk for $2 \mathrm{~h}$ at room temperature, the membranes were incubated with the primary antibodies (1:1,000 dilution) against p75NTR, CD133, SOX2, OCT4 (Santa Cruz biotechnology, Santa Cruz, CA, USA), CD44 (R\&D Systems Inc., Minneapolis, MN, USA) and $\beta$-actin (rabbit polyclonal, Sigma-Aldrich) at $4^{\circ} \mathrm{C}$ overnight. After rinsing with Tris-buffered saline containing Tween20 , the membrane was washed with $0.05 \%$ PBS and incubated with the horseradish peroxidase-conjugated secondary antibody for one hour at room temperature. Then the blots were visualized using a SuperSignal West Pico Chemiluminescent Substrate (Pierce Biotechnology, Inc., Rockford, IL, USA).

Radiation sensitivity assay. C6p75+ and C6p75+++ cells were seeded at a density of $1 \times 10^{5}$ cells per plate. Next, the cells were treated with $0,3,6$, or $9 \mathrm{~Gy}$ of radiation for $24 \mathrm{~h}$. Cell viability was measured by trypan blue staining $48 \mathrm{~h}$ after treatment. Adherent and suspended cells were collected and mixed with $0.4 \%$ of $2 \times$ trypan blue buffer. The cell density was adjusted to $1 \times 10^{6}$ cells $/ \mathrm{ml}$; subsequently, $10 \mu \mathrm{l}$ of the cell mixture was used for cell counting with a hemocytometer under a microscope. Dead cells were stained blue and excluded; the number of viable cells was counted. The mean and standard deviation (SD) were calculated.

Propidium iodide (PI) index analysis. After irradiation, C6p75+ and C6p75+++ cells were washed twice with ice-cold PBS, fixed with $70 \%$ ice-cold ethanol, and stored overnight at $4^{\circ} \mathrm{C}$. After centrifugation, $100 \mathrm{mg} / \mathrm{l}$ RNase and $5 \mathrm{~g} / \mathrm{l}$ PI were added to each tube; cells were stained in the dark for $30 \mathrm{~min}$. The distribution of cells in respective phases of the cell cycle was then analyzed using flow cytometry.

Clonogenic survival assay. C6p75+ and C6p75+++ cells were seeded at a density of $1 \times 10^{2}, 1 \times 10^{3}, 2 \times 10^{3}$, and $1 \times 10^{4}$ cells per plate and were then subjected to radiation at $0,3,6$, and $9 \mathrm{~Gy}$, respectively. After irradiation for $24 \mathrm{~h}$, cells were cultured for 2 weeks before being fixed with methanol and stained with $0.5 \%$ crystal violet. Only colonies containing more than 50 cells were 
counted and recorded. Survival was evaluated using the surviving fraction method, with the following formula:

1. Plating efficiency=colony number/number of cells seeded

2. Surviving fraction=colony number/

(number of cells seeded $\times$ plating efficiency)

Chemotherapy sensitivity assays. C6p75+ and C6p75+++ cells were seeded at a density of $1 \times 10^{4}$ per plate and were incubated for $24 \mathrm{~h}$. Next, cells were treated with temozolomide (TMZ) at a concentration of $0,50 \mu \mathrm{M}, 100 \mu \mathrm{M}$, and $200 \mu \mathrm{M}$ for $24 \mathrm{~h}$ at $37^{\circ} \mathrm{C}$, followed by assessment of their viability using the tetrazolium salt (XTT) assay. At the end of the treatment, the XTT mixture $(15 \mu \mathrm{M})$ and PMS $(25 \mu \mathrm{M})$ were added to each well; cells were then incubated for $4 \mathrm{~h}$ at $37^{\circ} \mathrm{C}$. The produced formazan dye was quantified by measuring the absorbance at wavelength of $490 \mathrm{~nm}$. In vivo tumorigenicity experiments. All animal experiments were approved by the Institutional Animal Care and Use Committee of the Chang-Gung Memorial Hospital (Chiayi, Taiwan, No.201402005). All Sprague Dawley rats were treated in accordance with institutional animal welfare guidelines. They were anesthetized using ketamine/xylazine mixture (ketamine $91 \mathrm{mg} / \mathrm{kg}$ and xylazine $9.1 \mathrm{mg} / \mathrm{kg}$ ) by intraperitoneal injection. C6p75+ and C6p75+++ cells were used for tumorigenic experiments. A cell suspension $(100 \mu \mathrm{l})$ was intracranially injected into four-week-old Sprague Dawley rats into their right hemisphere using a $100 \mu \mathrm{l}$ microsyringe, similarly to the previously described method (35). In the present study, the injected cell numbers were $1 \times 10^{3}$ and $1 \times 10^{5}$. The survival time of tumor-bearing rats was recorded. Sprague Dawley rats were euthanized once all spontaneous movement was lost, and the survival time was noted.

Statistical analysis. Data in the figures and text represent the mean \pm SD of three individual experiments. Statistical analyses were performed using the SPSS statistical software package (SPSS/PC+, SPSS Inc., Chicago, IL, USA). Between-group comparisons of continuous variables were analyzed with Student's $t$-test or analysis of variance. A two-tailed $p$-value of $<0.05$ was considered statistically significant.

\section{Results}

C6 cells can form neurospheres and express specific stemlike cell-related markers. Previous studies have reported the association between neurosphere formation and tumorinitiating cells (36-38). To investigate the ability of neurosphere formation, C6 glioma cells were plated at a density of $5 \times 103$ cells/well in an ultra-low attachment plate with serum-free stem cell conditioned medium. After seven days of cultivation, neurosphere formation was observed (Figure 1A). Over the following days, gradual enlargement in the size of the neurospheres was observed, and they were maintained in a smooth round configuration. The expression of cell markers related to tumor initiation was assessed using the protein lysate of C6 neurospheres. Compared to C6 expression in parental cells, immunoblotting revealed that CD44, CD133, OCT4, SOX2, and p75NTR were upregulated in $\mathrm{C} 6$ neurospheres (Figure 1B).
C6 cells with p75NTR overexpression aggregate to form neurospheres. To further investigate the relationship between p75NTR expression and neurosphere formation, we collected C6p75+++ and C6p75+ cells using the flow cytometry sorting technique (Figure 2A). Osman et al. have defined the highest and lowest $5 \%$ of p75NTR-expression cells as p75NTR high and p75NTR low cells (38). In our study, however, the numbers of the highest and lowest $5 \%$ of p75NTR-expression were extremely small, making these cells unrepresentative and unsuitable for comparison with the wide type C6 cells. Therefore, we excluded these extreme samples and defined the remaining higher and lower $25 \%$ of p75NTR-expression cells as p75NTR high and p75NTR low cells, in order to make the numbers of C6 parental, C6p75+ and C6p75+++ cells more comparable. Expression of p75NTR in C6 parental cells, C6p75+ cells, and C6p75+++ cells was confirmed using western blotting (Figure 2B). C6p75+++ cells showed the highest expression of p75NTR, while C6p75+ cells showed the lowest expression of p75NTR. Immunoblotting revealed that C6p75+++ cells showed the highest expression of CD44 and CD133, while C6p75+ cells showed the lowest expression of these markers. However, unlike the up-regulation of SOX2 in C6 neurospheres, SOX2 expression was lower in C6p75+++ cells than in C6p75+ cells.

Furthermore, parental C6 cells, C6p75+ cells, and C6p75+++ cells were subjected to the sphere-formation assay. Although all three subtypes of the C6 cells could aggregate to form neurospheres (Figure 2C), they differed in their ability to maintain the shape and size. C6p75+ cells could only maintain smaller and less compact neurospheres than C6 parental cells. On the other hand, C6p75+++ cells could aggregate more tightly to form neurospheres with larger diameters than C6 parental cells during the same observation periods.

Moreover, the proliferation ability of cells was evaluated using the colony formation assay. After a 14-day culture period, anchorage-independent spheres formed by C6 parental cells, C6p75+ cells, and C6p75+++ cells were stained with crystal violet, and the number of spheres was counted under a microscope. C6p75+++ cells generated more colonies than C6p75+ or C6 parental cells (Figure 2D). This indicates that $\mathrm{C} 6 \mathrm{p} 75+++$ cells have a greater ability to form neurospheres.

C6 cells with p75NTR overexpression display resistance to radiotherapy in vitro. In case of gliomas, radiation is part of the standard treatment. Therefore, the radiosensitivity between parental cells and C6p75+++ cells was compared. C6p75+ and C6p75+++ cells were seeded at a density of $1 \times 10^{5}$ per plate; subsequently, cells were exposed to ionizing radiation at $0,3,6$, and 9 Gy for $24 \mathrm{~h}$. The acute effects of irradiation on the survival of cells were assessed $48 \mathrm{~h}$ later. 
The results showed that after the same irradiation exposure dose, there were more viable C6p75+++ cells remaining (Figure 3A).

In addition, apoptotic levels after irradiation were evaluated by PI staining. The PI index assay was then performed after irradiation. The data showed an increased number of apoptotic cells with a higher dose of irradiation. After receiving the same dose of radiation, there were less apoptotic cells in the C6p75+++ group than in the C6p75+ group (Figure 3B).

Furthermore, the possible delayed effect of irradiation on clonogenic proliferation was evaluated. C6p75+ and C6p75+++ cells were seeded at a density of $1 \times 10^{2}, 1 \times 10^{3}$, $2 \times 10^{3}$, and $1 \times 10^{4}$ cells per plate before undergoing irradiation at $0,3,6$, and $9 \mathrm{~Gy}$, respectively. After irradiation, cells were cultured for two weeks. Then, cells were stained with crystal violet, and colonies with diameters larger than $2 \times 104$ were counted. Colony proliferation was then checked. Our results showed higher colony formation in the C6p75+++ group than in the C6p75+ group (Figure 3C). Moreover, the difference in the number of colonies between the C6p75+++ and C6p75+ groups was more obvious with the higher dose of radiation. The surviving fraction of the cells was also calculated. The results showed that C6p75+++ cells had a significant higher survival fraction than C6p75+ cells (Figure 3D). Therefore, considering these data, p75NTR up-regulation might be implicated in the resistance of C6 glioma cells to radiotherapy.

C6 cells with p75NTR overexpression display resistance to chemotherapy in vitro. Because TMZ is also used within the standard chemotherapy regime for glioblastoma multiforme (GBM) patients, it was investigated whether p75NTR expression can modulate the sensitivity of C6 glioma cells to TMZ. C6p75+ and C6p75+++ cells treated with TMZ at concentrations of $0 \mu \mathrm{M}, 50 \mu \mathrm{M}, 100 \mu \mathrm{M}$, and $200 \mu \mathrm{M}$ for 24 $\mathrm{h}$ and the survival was assessed using the XTT assay. The results showed that higher the dose of TMZ caused greater reduction in the number of remaining viable cells. However, there were more viable cells in the C6p75+++ group than in the C6p75+ group after treatment with the same concentration of TMZ (Figure 4A).

We further compared the expression of stem cell markers before and after treatment with TMZ. For this, C6 parental, C6p75+, and C6p75+++ cells were treated with TMZ at a concentration of $100 \mu \mathrm{m}$ for $48 \mathrm{~h}$ prior to immunoblotting. Up-regulation of stem cell markers was observed after TMZ treatment. In this regard, CD133 and OCT4 levels were increased after TMZ treatment in C6 parental, C6p75+, and C6p75+++ cells (Figure 4B).

C6 cells overexpressing p75NTR enhance tumorigenicity in vivo. From the above results in present study, overexpression of p75NTR in C6 glioma cells appeared to
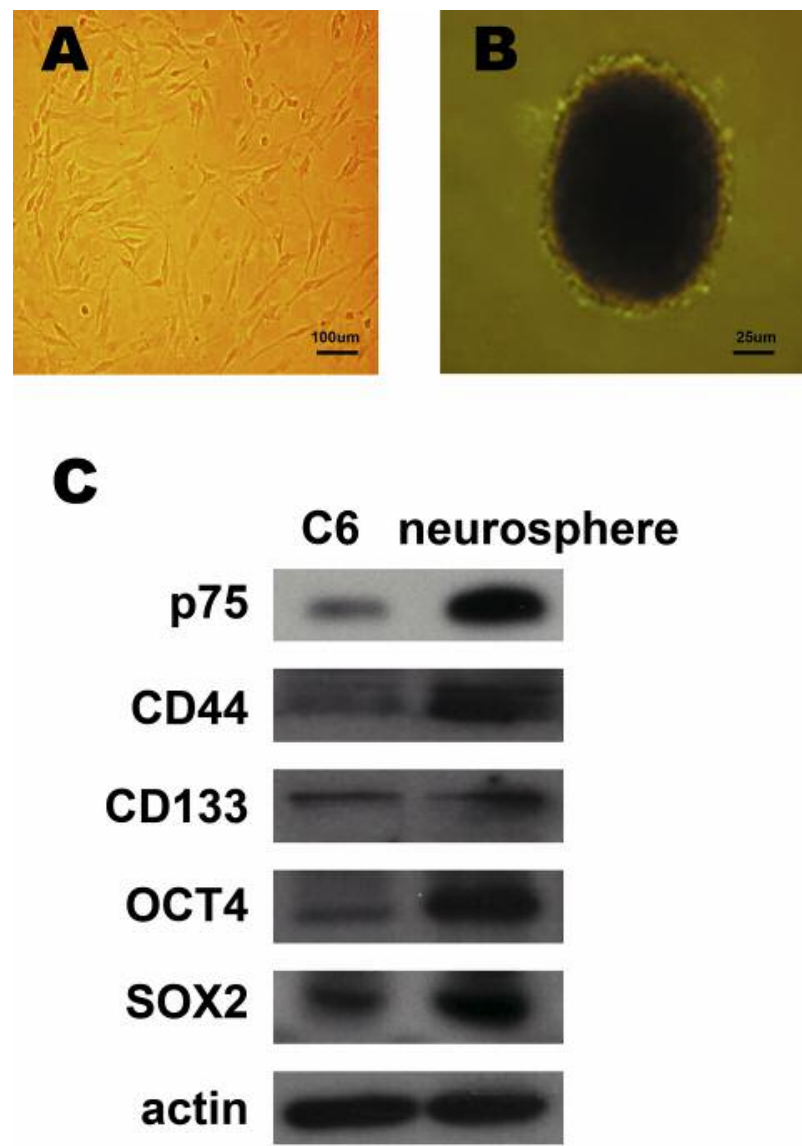

Figure 1. Neurosphere formation by C6 cells. (A) Sphere-forming assay. C6 cells were seeded on an ultra-low attachment plate at a density of $5 \times 10^{3}$ cells/well. (B) After 7-14 days of cultivation, neurosphere formation was observed in the sphere-forming assay (200x). (C) The cell lysates of both C6 parental cells and C6 neurospheres were analyzed by immunoblotting with anti-p75NTR, anti-CD44, anti-CD133, anti-OCT4, anti-SOX2, and anti-actin antibodies.

confer resistance to radio- and chemotherapy in vitro. Therefore, we further investigated the tumor-initiating capability of C6p75+++ glioma cells using an in vivo model. Sprague Dawley rats were implanted intracranially with different amounts of C6p75+ or C6p75+++ cells. After implantation, the movement status of the rats was observed. Once spontaneous movement was completely lost, the rats were euthanized and their survival times were recorded.

Our results revealed that rats receiving C6p75+++ cells had a lower survival rate than those receiving C6p75+ cells, irrespective of whether they received $1 \times 10^{3}$ or $1 \times 10^{5}$ cells (Figure 4C). In addition, injection with $1 \times 10^{5}$ cells resulted in a lower survival rate than injection with $1 \times 10^{3}$ cells. Moreover, using C6p75+++ cells, the survival rate of Sprague Dawley rats was lower, even when injected with 
A
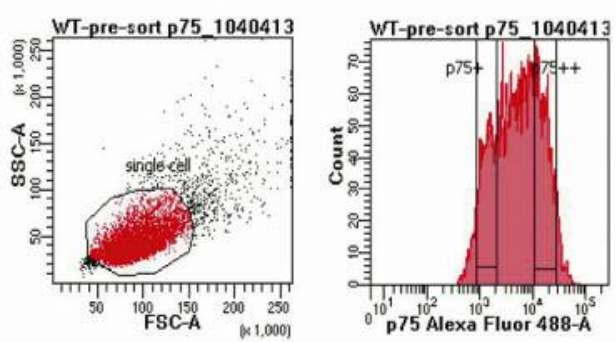

C

C6
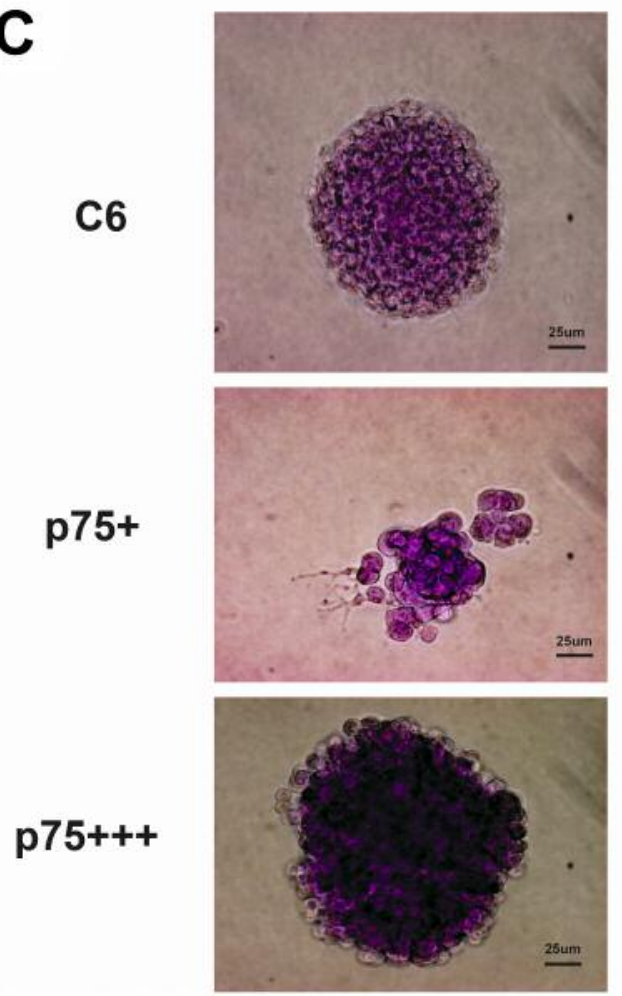

B

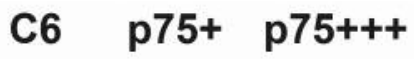

p75

CD44

CD133

sox2

actin
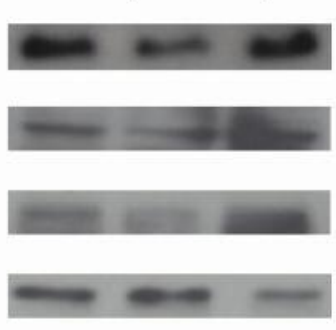

(1)

D
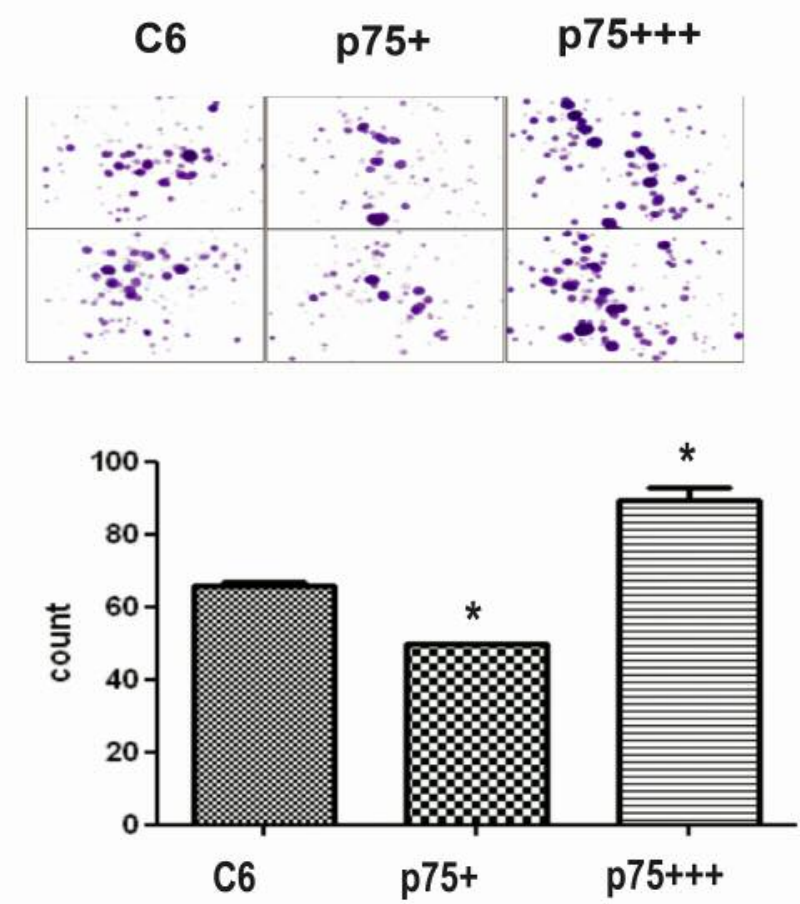

Figure 2. C6 cells overexpressing p75NTR aggregate to form neurospheres. (A) C6 cells were stained with an anti-p75NTR antibody, and fluorescence-activated cells were sorted using flow cytometry. Based on p75NTR expression, the highest $25 \%$ of cells were defined as C6p75+++ and the lowest $25 \%$ of cells were defined as C6p75+. (B) C6 parental, C6p 75+++, and C6p75+ cells were immunostained with anti-p75NTR, anti-CD44, anti-CD144, and anti-SOX2 antibodies. (C) The ability to form neurospheres was evaluated using the sphere-forming assay. (D) For colony formation analysis, six-well plates contained two layers of SeaPlaque Agarose. The bottom layer consisted of 0.6\% agarose, DMEM, and $10 \%$ FBS. C6 cells were then mixed with $0.3 \%$ agarose and placed in the six-well plates as the top layer. After culture for 10 days, cells were fixed and stained with $0.5 \mathrm{ml}$ of $0.005 \%$ crystal violet overnight. Colonies were counted under a microscope, and the number of colonies containing more than 50 cells was calculated (columns, mean; bars, $S D$; $* 00.01$ ).

only $1 \times 10^{3}$ cells, than the survival rate seen following the injection of C6p75+ cells at $1 \times 10^{5}$ (Figure 4D). These findings support that p75NTR overexpression may have a more important role in determining the tumorigenicity of C6 glioma cells than the number of glioma cells.

\section{Discussion}

Accumulating evidence has suggested that p75NTR proteolysis is required for BTIC proliferation and that it can promote the growth of BTIC $(34,39)$. To further elucidate 
A
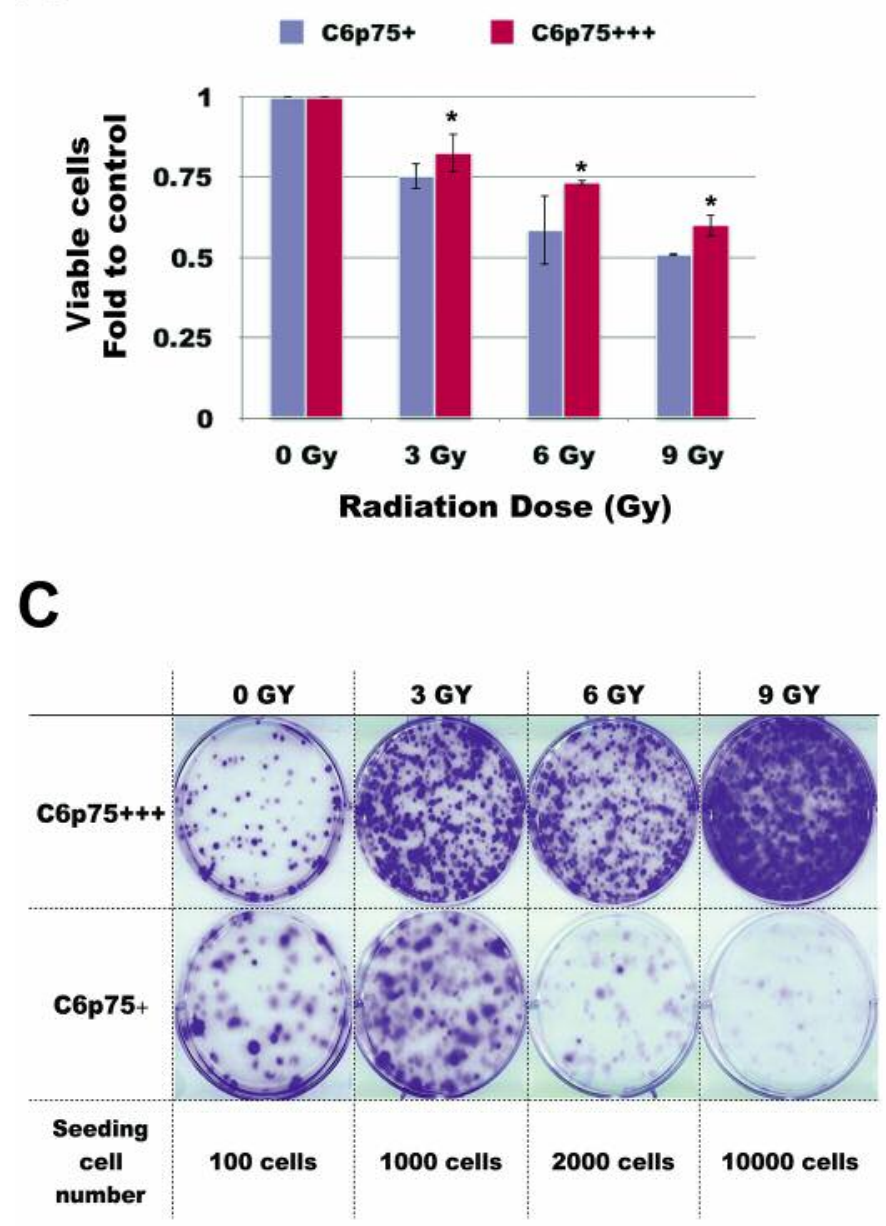

B

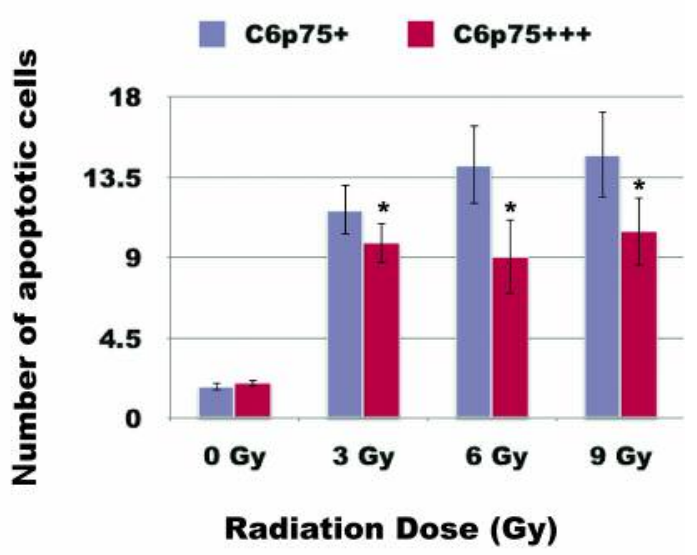

D

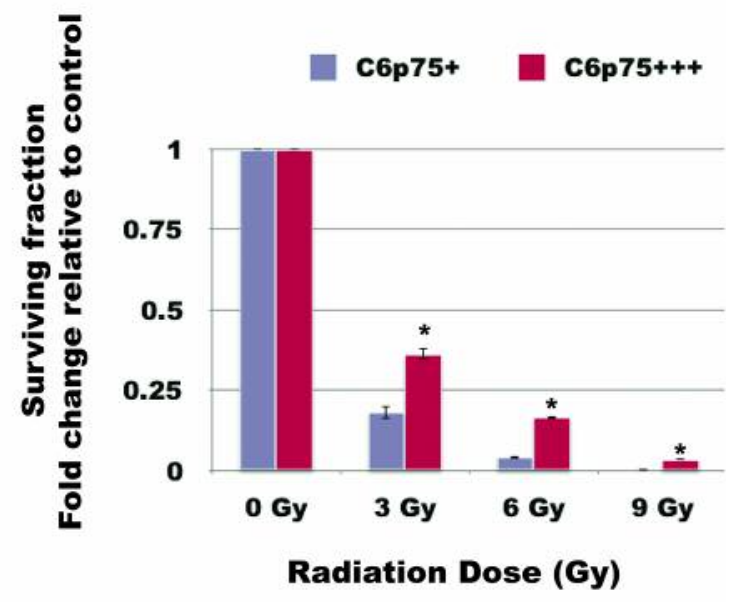

Figure 3. Resistance of C6p75+ and C6p75+++ cells to radiotherapy in vitro. (A) Radiation sensitivity assay. Both groups of cells were seeded at a density of $1 \times 10^{5}$ per plate and treated with $0,3,6$, and 9 Gy of radiation for $48 \mathrm{~h}$. Cells were collected and mixed with $0.4 \%$ of $2 \times$ trypan blue. The cell density was adjusted to $1 \times 10^{6} \mathrm{cells} / \mathrm{ml}$, and the number of viable cells was calculated after the exclusion of dead cells $(* p<0.01)$. (B) PI index analysis. C6p75+ and C6p75+++ cells were seeded at a density of $1 \times 10^{4}$ per plate. After irradiation with 0, 3, 6, and 9 Gy, cells were washed and fixed with ethanol. Cells were then mixed with PI and stained in the dark. The distribution of cells in each cell cycle phase was analyzed using flow cytometry (columns, mean; bars, $S D ; * p<0.01)$. (C and D) Clonogenic survival assay. Both C6p $75+$ and C6p $75+++$ cells were seeded at a density of $1 \times 10^{2}, 1 \times 10^{3}, 2 \times 10^{3}$, and $1 \times 10^{4}$ cells per plate prior to undergoing irradiation at $0,3,6$, and 9 Gy, respectively. After irradiation, cells were cultured for two weeks before being fixed and were stained with crystal violet. The numbers of colonies were counted and recorded, and survival was evaluated using the surviving fraction formula.

whether p75NTR plays a role in BTIC-related features, glioma cells expressing different levels of p75NTR were isolated by cell sorting, and the relationship between the expression of p75NTR and common features of BTICs including self-renewal and high resistance to radio- and chemotherapy was investigated.

To investigate the self-renewal ability, one of the most important hallmarks of BTICs, the sphere-forming ability in serum-free medium is commonly used (40-43). In our previous studies, C6 glioma cells were shown to aggregate and form neurospheres under special condition, such as starving environment (data not shown). Herein, the neurosphereformation assay was performed for C6 glioma cells and revealed that the expression of stem cell markers, such as CD133, CD44, OCT4, and SOX2, was increased in neurospheres compared to $\mathrm{C} 6$ parental cells. Interestingly, p75NTR expression was also significantly increased in C6 neurospheres. However, whether p75NTR expression was increased during neurosphere formation or only high-expression p75NTR cells can form neurospheres remains to be determined.

To investigate the role of p75NTR in neurosphere formation, C6 cells expressing different levels of p75NTR 
A

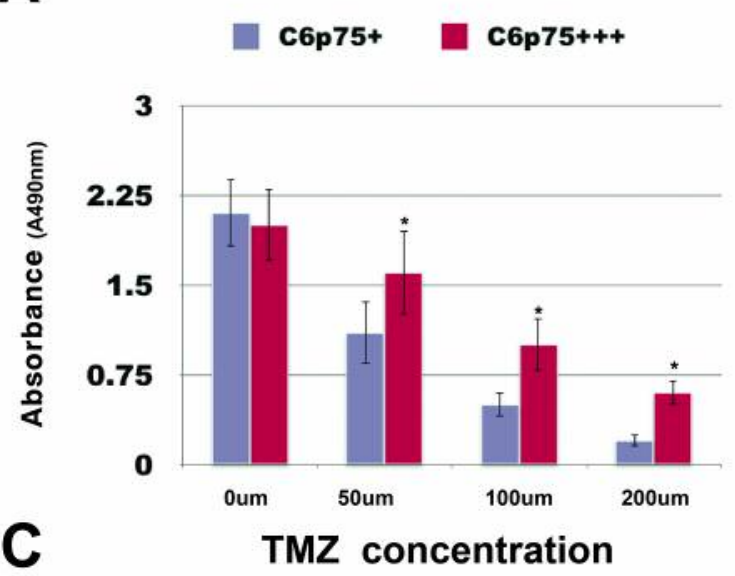

B
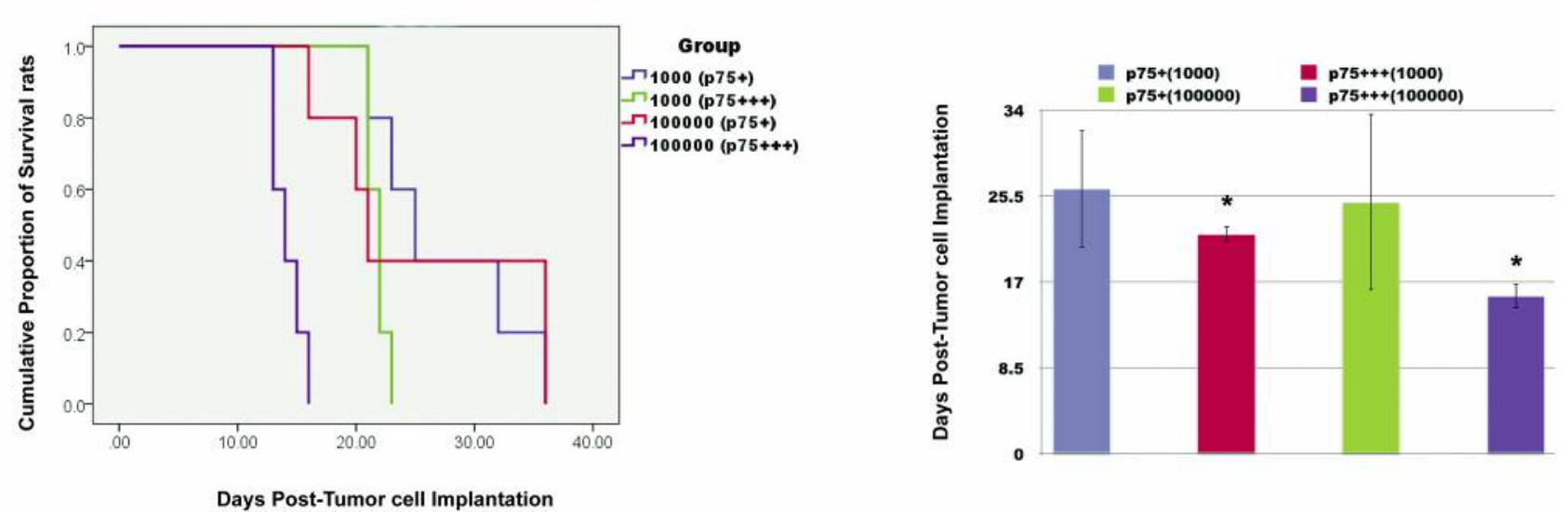

Figure 4. Resistance of C6p75+ and C6p75+++ cells to chemotherapy in vitro. C6p75+ and C6p75+++ cells were seeded at a density of $1 \times 10^{4}$ per plate and incubated for $24 \mathrm{~h}$. Cells were then treated with TMZ at concentrations of $0,50 \mathrm{M}, 100 \mu \mathrm{M}$, and $200 \mathrm{M} \mathrm{for} 24 \mathrm{~h}$. (A) TMZ sensitivity assays for C6p75+ and C6p75+++ cells after TMZ treatment. Cell viability was assessed using the XTT assay. Cells were incubated with XTT solution for $4 \mathrm{~h}$, and the absorbance of the plates was measured at $490 \mathrm{~nm}$. Each experiment was repeated three times (columns, mean; bars, SD; $\left.{ }^{*} p<0.01\right)$. (B) Comparison of stem cell markers before and after TMZ treatment. Cells were immunostained with anti-CD133, anti-OCT4, and antiSOX2 antibodies for western blotting. (C) Tumorigenicity and expression of p 75NTR in vivo. C6p $75+$ and C6p $75+++$ cells were stereotactically implanted into Sprague Dawley rats into the right hemisphere. Each cell type was injected at cell numbers of $1 \times 10^{3}$ and $1 \times 10^{5}$. After implantation, the movement status of the rats was observed daily. Sprague Dawley rats were euthanized once spontaneous movement was completely lost, and the survival time was recorded. The figure shows the cumulative proportion of the survival rate. (D) The survival time of Sprague Dawley rats was analyzed (columns, mean; bars, $S D ; * p<0.01$ ).

were subjected to the sphere-formation assay. Results showed that C6p75+++ cells steadily aggregated to form neurospheres that were smooth and round. In addition, C6p75+++ cells showed an ability to generate more colonies than the other two types of cells. As sphere formation and clonal proliferation are unique properties of stem-like cells (44), our results suggest that C6p75+++ cells possess certain stem-like cell characteristics.

Many surface markers have been reported to characterize BTICs, such as CD133, CD15/SSEA, A2B5, Notch, CD44, and STAT3 $(45,46)$, but there is no consensus on the best stemness marker. When the expression of well-known stem cell markers was evaluated, it was shown that C6p75+++ cells had higher expression of CD133 and CD44 but lower expression of SOX2 than C6p75+ cells. In addition, CD133 and OCT4 expression were increased after TMZ treatment. Osman et al. have reported that p75NTR expression can be increased during the dedifferentiation process (38). These results suggested that the expression of stemness markers and $\mathrm{p} 75 \mathrm{NTR}$ can be regulated during neurosphere formation and with TMZ treatment (Figure 1).

Another key feature of BTICs is resistance to chemo- and radiotherapy, which are critical issues in anti-cancer therapy. Bao et al. reported that CD133+ glioma cells have higher 
resistance to irradiation than CD133- cells (47); this resistance was attributed to a decreased rate of apoptosis rate and the activation of checkpoint responses. Currently, several signaling pathways, such as the Notch and tyrosine kinase pathways, are associated with resistance of glioma stem-like cells to radiotherapy (13). In glioma stem-like cells, CD133+ cells induce resistance to $\mathrm{TMZ}$ through the overexpression of O6-methylguanine-DNA-methyltransferase (48). The effects of TMZ treatment on glioma cells have been reported to induce conversion from non-glioma stem cells (GSCs) to GSCs (49). Beier et al. have reported an increased GSC population after TMZ treatment (50). Auffinger et al. used the recurrent GBM model to demonstrate the conversion of CD133-negative cells to CD133+ cells after chemotherapy (51). For analyzing the role of p75NTR in conferring resistance to radiotherapy, we performed PI index analysis (52), colonogenic assay (53), and survival fraction analysis (13). C6p75+++ cells were more viable after TMZ treatment and showed greater colony proliferation than C6p75+ cells after irradiation. These results suggested that C6 cells with overexpressed p75NTR are resistant to chemo- and radiotherapy. However, owing to the complex underlying mechanism for the role of p75NTR in the tumorigenesis such as invasiveness, apoptosis, resistance to chemo- and radiotherapy, more work is needed in the future.

In previous studies, p75NTR has been demonstrated to be associated with tumorigenicity in melanomas, prostate cancers, and squamous cell carcinomas $(30,54-57)$. In our previous study, knockdown of p75NTR was able to enhance the invasion and migration of C6 cells and p75NTR expression was higher in malignant gliomas than in benign gliomas (32). In the present study, Sprague Dawley rats injected with C6p75+++ cells had a shorter survival time than those injected with C6p75+ cells. Moreover, when rats were injected with C6p75+ cells, the survival time was similar, irrespective of the number of the administered cells. However, when rats were injected with C6p75+++ cells, the survival time using $1 \times 10^{5}$ cells further decreased compared with that when $1 \times 10^{3}$ cells were used. This reveals that $\mathrm{p} 75 \mathrm{NTR}$ expression may be a more dominant factor in affecting the survival time in tumor initiation rather than the number of C6 cells injected. These results support that $\mathrm{p} 75 \mathrm{NTR}$ overexpression might enhance the tumorigenicity of C6 glioma cells.

BTICs were thought to be the key factor underlying GBM recurrence and treatment failure. However, it has recently been suggested that more than one type of BTIC exist. Chen et al. have shown the existence of multiple types of cancer stem-like cells (58), which was confirmed by Dahan et al. (59). Therefore, a better understanding of the heterogeneous composition of BTICs is required for allowing the precise development of customized therapeutic strategies. Currently, there are various techniques to identify BTICs, including surface markers, the sphere-forming assay, and drug- resistance cell isolation. However, due to the heterogeneous nature of gliomas, additional methods will be needed in the future.

\section{Conclusion}

C6p75+++ cells demonstrated several stem-like characteristics, namely, sphere-formation, increased stem cell marker expression, and higher colony proliferation. In addition, C6p75+++ cells demonstrated resistance to radioand chemotherapy. In vivo, C6p75+++ cells showed further enhanced tumorigenicity. Although the underlying mechanisms remain to be determined, glioma cells with p75NTR overexpression may function as tumor-initiating cells and can be treatment targets in the future.

\section{Consent for Publication}

All animal experimental protocols were approved by the Institutional Animal Care and Use committee of Chang-Gung Memorial Hospital, Chia-Yi branch (No. 2014102005).

\section{Availability of Data and Materials}

The datasets generated during and analyzed during the current study are available from the corresponding Author on reasonable request

\section{Competing Financial Interests}

The Authors declare no competing financial interests.

\section{Acknowledgements}

This study was supported by grants from Chang Gung Memorial Hospital, Chia-yi Branch (CMRPG6E0051, CMRPG6E0052, CMRPG6F0691, CMRPG6C0102, and CMRPG6F0121).

\section{References}

1 Stupp R: European Organisation for Research and Treatment of Cancer Brain Tumor and Radiotherapy Groups; National Cancer Institute of Canada Clinical Trials Group. Radiotherapy plus concomitant and adjuvant temozolomide for glioblastoma. $\mathrm{N}$ Engl J Med 352(10): 987-996, 2005.

2 Taylor LP: Diagnosis, treatment, and prognosis of glioma five new things. Neurology 75(18 Suppl 1): S28-S32, 2010.

3 Louis DN, Ohgaki H, Wiestler OD, Cavenee WK, Burger PC, Jouvet A, Scheithauer BW and Kleihues P: The 2007 WHO classification of tumours of the central nervous system. Acta Neuropathol 114(2): 97-109, 2007.

4 Greaves M and Maley CC: Clonal evolution in cancer. Nature 481(7381): 306-313, 2012.

5 Campbell PJ, Pleasance ED, Stephens PJ, Dicks E, Rance R, Goodhead I, Follows GA, Green AR, Futreal PA and Stratton MR: Subclonal phylogenetic structures in cancer revealed by ultra-deep sequencing. Proc Natl Acad Sci 105(35): 1308113086, 2008. 
6 Ding L, Ellis MJ, Li S, Larson DE, Chen K, Wallis JW, Harris CC, McLellan MD, Fulton RS and Fulton LL: Genome remodelling in a basal-like breast cancer metastasis and xenograft. Nature 464(7291): 999-1005, 2010.

7 Navin N, Kendall J, Troge J, Andrews P, Rodgers L, McIndoo J, Cook K, Stepansky A, Levy D and Esposito D: Tumour evolution inferred by single-cell sequencing. Nature 472(7341): 90-94, 2011

8 Clarke MF, Dick JE, Dirks PB, Eaves CJ, Jamieson CH, Jones DL, Visvader J, Weissman IL and Wahl GM: Cancer stem cells-perspectives on current status and future directions: AACR workshop on cancer stem cells. Cancer Res 66(19): 9339-9344, 2006

9 Jordan CT, Guzman ML and Noble M: Cancer stem cells. N Engl J Med 355(12): 1253-1261, 2006.

10 Dalerba P, Cho RW and Clarke MF: Cancer stem cells: Models and concepts. Annu Rev Med 58: 267-284, 2007.

11 Bonnet D and Dick JE: Human acute myeloid leukemia is organized as a hierarchy that originates from a primitive hematopoietic cell. Nat Med 3(7): 730-737, 1997.

12 Yuan X, Curtin J, Xiong Y, Liu G, Waschsmann-Hogiu S, Farkas DL, Black KL and John SY: Isolation of cancer stem cells from adult glioblastoma multiforme. Oncogene 23(58): 9392-9400, 2004.

13 Wang J, Wakeman TP, Lathia JD, Hjelmeland AB, Wang XF, White RR, Rich JN and Sullenger BA: Notch promotes radioresistance of glioma stem cells. Stem Cells 28(1): 17-28, 2010.

14 Bertrand J, Begaud-Grimaud G, Bessette B, Verdier M, Battu S and Jauberteau M-O: Cancer stem cells from human glioma cell line are resistant to FAS-induced apoptosis. Int J Oncol 34(3): 717-727, 2009.

15 Jiang X, Zhao Y, Smith C, Gasparetto M, Turhan A, Eaves A and Eaves C: Chronic myeloid leukemia stem cells possess multiple unique features of resistance to BCR-ABL targeted therapies. Leukemia 21(5): 926-935, 2007.

16 Shen S, Yang W, Wang Z, Lei X, Xu L, Wang Y, Wang L, Huang $\mathrm{L}$, Yu Z and Zhang X: Tumor-initiating cells are enriched in CD44 hi population in murine salivary gland tumor. PLoS One 6(8): e23282, 2011.

17 Prince M, Sivanandan R, Kaczorowski A, Wolf G, Kaplan M, Dalerba P, Weissman I, Clarke M and Ailles L: Identification of a subpopulation of cells with cancer stem cell properties in head and neck squamous cell carcinoma. Proc Natl Acad Sci 104(3): 973-978, 2007.

18 Jemal A, Bray F, Center MM, Ferlay J, Ward E and Forman D: Global cancer statistics. CA Cancer J Clin 61(2): 69-90, 2011.

19 Wei XD, Zhou L, Cheng L, Tian J, Jiang JJ and MacCallum J: In vivo investigation of $\mathrm{CD} 133$ as a putative marker of cancer stem cells in Hep-2 cell line. Head Neck 31(1): 94-101, 2009.

20 Zhang Q, Shi S, Yen Y, Brown J, Ta JQ and Le AD: A subpopulation of CD133+ cancer stem-like cells characterized in human oral squamous cell carcinoma confer resistance to chemotherapy. Cancer Lett 289(2): 151-160, 2010.

21 Zhou L, Wei X, Cheng L, Tian J and Jiang JJ: CD133, one of the markers of cancer stem cells in Hep-2 cell line. Laryngoscope 117(3): 455-460, 2007.

22 Dontu G, Abdallah WM, Foley JM, Jackson KW, Clarke MF, Kawamura MJ and Wicha MS: In vitro propagation and transcriptional profiling of human mammary stem/progenitor cells. Genes Dev 17(10): 1253-1270, 2003.
23 Suzuki A, Oyama K, Fukao K, Nakauchi H and Taniguchi H: Establishment of clonal colony-forming assay system for pancreatic stem/progenitor cells. Cell Transplant 11(5): 451-453, 2002.

24 Cragnolini $\mathrm{AB}$ and Friedman WJ: The function of p75 NTR in glia. Trends Neurosci 31(2): 99-104, 2008.

25 Gentry JJ, Casaccia-Bonnefil P and Carter BD: Nerve growth factor activation of nuclear factor $\varkappa b$ through its $\mathrm{p} 75$ receptor is an anti-apoptotic signal in RN22 schwannoma cells. J Biol Chem 275(11): 7558-7565, 2000.

26 Boyd J and Gordon T: The neurotrophin receptors, TrkB and p75, differentially regulate motor axonal regeneration. Dev Neurobiol 49(4): 314-325, 2001.

27 Bentley CA and Lee K-F: P75 is important for axon growth and Schwann cell migration during development. J Neurosci 20(20): 7706-7715, 2000.

28 Anton ES, Weskamp G, Reichardt LF and Matthew WD: Nerve growth factor and its low-affinity receptor promote Schwann cell migration. Proc Natl Acad Sci 91(7): 2795-2799, 1994.

29 Civenni G, Walter A, Kobert N, Mihic-Probst D, Zipser M, Belloni B, Seifert B, Moch H, Dummer R and van den Broek M: Human CD271-positive melanoma stem cells associated with metastasis establish tumor heterogeneity and long-term growth. Cancer Res 71(8): 3098-3109, 2011.

30 Okumura T, Tsunoda S, Mori Y, Ito T, Kikuchi K, Wang TC, Yasumoto S and Shimada Y: The biological role of the lowaffinity p75 neurotrophin receptor in esophageal squamous cell carcinoma. Clin Cancer Res 12(17): 5096-5103, 2006.

31 Imai T, Tamai K, Oizumi S, Oyama K, Yamaguchi K, Sato I, Satoh K, Matsuura K, Saijo S and Sugamura K: CD271 defines a stem cell-like population in hypopharyngeal cancer. PLoS One 8(4): e62002, 2013.

32 Wang T-C, Luo S-j, Lin C-L, Chang P-J and Chen M-F: Modulation of p75 neurotrophin receptor under hypoxic conditions induces migration and invasion of C6 glioma cells. Clin Exp Metastasis 32(1): 73-81, 2015.

33 Khwaja F, Tabassum A, Allen J and Djakiew D: The p75 NTR tumor suppressor induces cell cycle arrest facilitating caspase mediated apoptosis in prostate tumor cells. Biochem Biophys Res Commun 341(4): 1184-1192, 2006.

34 Forsyth PA, Krishna N, Lawn S, Valadez JG, Qu X, Fenstermacher DA, Fournier M, Potthast L, Chinnaiyan P and Gibney GT: P75 neurotrophin receptor cleavage by $\alpha$-and $\gamma$-secretases is required for neurotrophin-mediated proliferation of brain tumor-initiating cells. J Biol Chem 289(12): 8067-8085, 2014.

35 Wang TC, Cheng CY, Yang WH, Chen WC and Chang PJ: Characterization of highly proliferative secondary tumor clusters along host blood vessels in malignant glioma. Mol Med Report 12(5): 6435-6444, 2015.

36 Cao L, Zhou Y, Zhai B, Liao J, Xu W, Zhang R, Li J, Zhang Y, Chen L and Qian H: Sphere-forming cell subpopulations with cancer stem cell properties in human hepatoma cell lines. BMC Gastroenterol 11(1): 71, 2011.

37 Chen S-F, Chang Y-C, Nieh S, Liu C-L, Yang C-Y and Lin Y-S: Nonadhesive culture system as a model of rapid sphere formation with cancer stem cell properties. PLoS One 7(2): e31864, 2012.

38 Osman TA, Parajuli H, Sapkota D, Ahmed IA, Johannessen AC and Costea DE: The low-affinity nerve growth factor receptor p75NTR identifies a transient stem cell-like state in oral squamous cell carcinoma cells. J Oral Pathol Med 44(6): 410$419,2015$. 
39 Lawn S, Krishna N, Pisklakova A, Qu X, Fenstermacher DA, Fournier M, Vrionis FD, Tran N, Chan JA and Kenchappa RS: Neurotrophin signaling via TrkB and TrkC receptors promotes the growth of brain tumor-initiating cells. J Biol Chem 290(6): 3814-3824, 2015.

40 Hueng D-Y, Sytwu H-K, Huang S-M, Chang C and Ma H-I: Isolation and characterization of tumor stem-like cells from human meningiomas. J Neurooncol 104(1): 45-53, 2011.

41 Min SO, Lee SW, Bak SY and Kim KS: Ideal sphere-forming culture conditions to maintain pluripotency in a hepatocellular carcinoma cell lines. Cancer Cell Int 15(1): 95, 2015.

42 Reynolds BA and Weiss S: Generation of neurons and astrocytes from isolated cells of the adult mammalian central nervous system. Science 255(5052): 1707-1710, 1992.

43 Zhong Y, Guan K, Guo S, Zhou C, Wang D, Ma W, Zhang Y, Li $\mathrm{C}$ and Zhang S: Spheres derived from the human SK-RC-42 renal cell carcinoma cell line are enriched in cancer stem cells Cancer Lett 299(2): 150-160, 2010.

44 Nduom EK-E, Hadjipanayis CG and Van Meir EG: Glioblastoma cancer stem-like cells-implications for pathogenesis and treatment. Cancer J (Sudbury, Mass) 18(1): 100, 2012.

45 Singh SK, Hawkins C, Clarke ID, Squire JA, Bayani J, Hide T, Henkelman RM, Cusimano MD and Dirks PB: Identification of human brain tumour initiating cells. Nature 432(7015): 396-401, 2004.

46 Mao X-G, Zhang X, Xue X-Y, Guo G, Wang P, Zhang W, Fei Z, Zhen H-N, You S-W and Yang H: Brain tumor stem-like cells identified by neural stem cell marker CD15. Transl Oncol 2(4): 247-257, 2009.

47 Bao S, Wu Q, McLendon RE, Hao Y, Shi Q, Hjelmeland AB, Dewhirst MW, Bigner DD and Rich JN: Glioma stem cells promote radioresistance by preferential activation of the DNA damage response. Nature 444(7120): 756-760, 2006.

48 Liu G, Yuan X, Zeng Z, Tunici P, Ng H, Abdulkadir IR, Lu L, Irvin D, Black KL and John SY: Analysis of gene expression and chemoresistance of CD133+ cancer stem cells in glioblastoma. Mol Cancer 5(1): 67, 2006.

49 Gupta PB, Fillmore CM, Jiang G, Shapira SD, Tao K, Kuperwasser $C$ and Lander ES: Stochastic state transitions give rise to phenotypic equilibrium in populations of cancer cells. Cell 146(4): 633-644, 2011.

50 Beier D, Röhrl S, Pillai DR, Schwarz S, Kunz-Schughart LA, Leukel P, Proescholdt M, Brawanski A, Bogdahn U and TrampeKieslich A: Temozolomide preferentially depletes cancer stem cells in glioblastoma. Cancer Res 68(14): 5706-5715, 2008.
51 Auffinger B, Tobias A, Han Y, Lee G, Guo D, Dey M, Lesniak $\mathrm{M}$ and Ahmed A: Conversion of differentiated cancer cells into cancer stem-like cells in a glioblastoma model after primary chemotherapy. Cell Death Differ 21(7): 1119-1131, 2014.

52 Mitteer RA, Wang Y, Shah J, Gordon S, Fager M, Butter P-P, Kim HJ, Guardiola-Salmeron C, Carabe-Fernandez A and Fan Y: Proton beam radiation induces DNA damage and cell apoptosis in glioma stem cells through reactive oxygen species. Sci Rep 5: 13961, 2015.

53 de Araujo PR, Gorthi A, da Silva AE, Tonapi SS, Vo DT, Burns SC, Qiao M, Uren PJ, Yuan Z-M and Bishop AJ: Musashi1 impacts radio-resistance in glioblastoma by controlling DNA-protein kinase catalytic subunit. Am J Pathol 186(9): 2271-2278, 2016.

54 Shonukan T, Bagayogo I, McCrea P, Chao M and Hempstead B: Neurotrophin-induced melanoma cell migration is mediated through the actin-bundling protein fascin. Oncogene 22(23): 3616-3623, 2003.

55 Boiko AD, Razorenova OV, van de Rijn M, Swetter SM, Johnson DL, Ly DP, Butler PD, Yang GP, Joshua B and Kaplan MJ: Human melanoma-initiating cells express neural crest nerve growth factor receptor CD271. Nature 466(7302): 133-137, 2010.

56 Redmer T, Welte Y, Behrens D, Fichtner I, Przybilla D, Wruck W, Yaspo M-L, Lehrach H, Schäfer R and Regenbrecht CR: The nerve growth factor receptor CD271 is crucial to maintain tumorigenicity and stem-like properties of melanoma cells. PLoS One 9(5): e92596, 2014.

57 Gravina GL, Marampon F, Sanità P, Mancini A, Colapietro A, Scarsella L, Jitariuc A, Biordi L, Ficorella C and Festuccia C: Increased expression and activity of p75NTR are crucial events in azacitidine-induced cell death in prostate cancer. Oncol Rep 36(1): 125-130, 2016.

58 Chen R, Nishimura MC, Bumbaca SM, Kharbanda S, Forrest WF, Kasman IM, Greve JM, Soriano RH, Gilmour LL and Rivers CS: A hierarchy of self-renewing tumor-initiating cell types in glioblastoma. Cancer Cell 17(4): 362-375, 2010.

59 Dahan P, Gala JM, Delmas C, Monferran S, Malric L, Zentkowski D, Lubrano V, Toulas C, Moyal EC-J and Lemarie A: Ionizing radiations sustain glioblastoma cell dedifferentiation to a stem-like phenotype through survivin: Possible involvement in radioresistance. Cell Death Dis 5(11): e1543, 2014.

Received July 5, 2018

Revised July 25, 2018

Accepted August 1, 2018 